\title{
STUDY ON AETIOLOGY \& RISK FACTORS IN SPONTANEOUS LATE PRETERM PREMATURE RUPTURE OF MEMBRANES
}

\author{
Ramakanta Sahoo1, Sushreesmita Mohanty²
}

1 Postgraduate Student, Department of Obstetrics and Gynaecology, Hi-Tech Medial College and Hospital, Bhubaneswar, Odisha, India. ${ }^{2}$ Associate Professor, Department of Obstetrics and Gynaecology, Hi-Tech Medial College and Hospital, Bhubaneswar, Odisha, India.

\begin{abstract}
BACKGROUND
ABSTRACT

Preterm premature rupture of membranes is the rupture of membranes during pregnancy before 37 weeks' gestation. It occurs in 3 percent of pregnancies and is the cause of approximately one third of preterm deliveries. It can lead to significant perinatal and maternal morbidity. Appropriate evaluation of aetiology \& risk factors helps in preventing PPROM and its related complications. We wanted to study the aetiology and risk factors of PPROM from 34-37 wks. of gestation. This is a descriptive study carried out in the department of obstetrics and gynecology, Hi-Tech Medical College \& Hospital, Bhubaneswar.
\end{abstract}

\begin{abstract}
METHODS
The present study is a descriptive study of risk factors in 100 cases of preterm premature rupture of membranes between 34-37 weeks' gestation with singleton pregnancy, from 1st Aug. 2016 to 31 st July 2018. Patients with medical complications like anemia, preexisting hypertension, diabetes, vascular or renal disease, multiple gestations, uterine or foetal anomalies etc. were excluded from the study. Detailed history was obtained, physical examination carried out, and appropriate management instituted as per individual patient's need.
\end{abstract}

\section{RESULTS}

In this study, the risk-factors of PPROM were low socioeconomic status (67\%), age group 21-30 yrs. (84\%), primigravida (61\%), irregular antenatal care (67\%), recent coitus (23\%), genital tract infection (21\%), E. coli (18\%) cases.

\section{CONCLUSIONS}

PPROM is one of the important causes of preterm birth that can result in high perinatal morbidity and mortality along with maternal morbidity. Looking after a premature infant puts immense burden on the family, economy and health care resources of the country. An understanding of risk-factors of PPROM and better antenatal care, can improve maternal and neonatal outcomes.

HOW TO CITE THIS ARTICLE: Sahoo R, Mohanty S. Study on aetiology \& risk factors in spontaneous late preterm premature rupture of membranes. J. Evolution Med. Dent. Sci. 2019;8(20):1624-1627, DOI: 10.14260/jemds/2019/359

\section{BACKGROUND}

Premature rupture of membranes (PROM) is defined as the spontaneous rupture of amniotic membrane with a release of amniotic fluid at least one hour before the onset of labour. If the membranes rupture after 37 weeks of gestation it is called term PROM. If the rupture of membranes (ROM) occur after 28 weeks but before 37 weeks of gestation is termed as the preterm premature rupture of membrane (PPROM). ${ }^{1}$

- $\quad$ Previable PROM - Before 23 weeks.

- PPROM remote from term - 23-31 weeks.

- $\quad$ PPROM near term - 32-33 weeks.

- $\quad$ PPROM near term - 34-36 weeks.

\section{Latent Period}

It is the time interval between the rupture of membranes and the onset of uterine contractions. ${ }^{2}$

\footnotetext{
'Financial or Other Competing Interest': None.

Submission 27-02-2019, Peer Review 30-03-2019,

Acceptance 05-04-2019, Published 20-05-2019.

Corresponding Author:

Dr. Sushreesmita Mohanty,

Associate Professor,

Department of Obstetrics and Gynaecology,

Hi-Tech Medial College and Hospital,

Bhubaneswar-751010, Odisha, India.

E-mail: drsushreesmita98@gmail.com

DOI: $10.14260 /$ jemds $/ 2019 / 359$

\section{Prolonged PROM}

It is the term used when more than 24 hours have elapsed before the labor ensues. ${ }^{2}$

\section{High Rupture of Membranes}

It is due to the rupture of amniochorion at a site distant from internal OS and spontaneous cessation of leakage can occur. ${ }^{2}$

In most pregnancies, labour begins in the presence of intact foetal membranes. Without intervention the membranes usually remain intact until approximately $8 \mathrm{~cm}$ of cervical dilation. The pressure necessary to cause membrane rupture experimentally not only is greater than the base line resting tone of the intrauterine cavity, but also generally exceeds that generated by normal labour. The clinical entity of PROM that can occur in the absence of labour with an cervix even at bed rest and also remote from term is an enigma that remains only imperfectly explained. Hence a number of hypothesis have been proposed in an attempt to explain its aetiology. At present, majority of instances of PROM probably are secondary to multiple factors.

ROM is usually followed by labor. The onset of labor after PROM is directly related to the gestational age at the time of rupture. Labor started within 24 hours of PROM in $81 \%$ of patients carrying babies larger than 2500 grams but early in gestation. Only $48 \%$ of the patients develop labor within three days of PROM.2 It is an obstetric conundrum which is poorly defined, with an obscure aetiology, difficult to diagnose and is associated with significant maternal and neonatal morbidity and mortality and has diverse and controversial management strategies. 


\section{Incidence of PROM}

PROM occurs in approximately $10 \%$ of all pregnancies and in $70 \%$ of the cases at term. Although there is some morbidity when PROM occurs in term pregnancies, the fundamental clinical problem is preterm PROM, a condition that occurs in $3 \%$ of all pregnancies and is responsible for approximately 30 $\%$ of all preterm deliveries. ${ }^{1}$

Preterm PROM complicates 3-8\% of pregnancies and leads to one third of preterm deliveries ${ }^{2}$. It increases the risk of prematurity and leads to other perinatal and neonatal complications with $1-2 \%$ risk of foetal death. PROM is associated with increased risk of chorioamnionitis, dysfunctional labor, increased cesarean rates, postpartum hemorrhage and endometritis in the mother. In the foetus, there is increased occurrence of hyaline membrane disease, intraventricular hemorrhage, sepsis, cord prolapse, foetal distress and increased foetal wastage.

Thus, earlier the gestational age at the time of PROM, longer is the latency and more the complications. Management of PROM remains controversial and challenging. ${ }^{2}$ Controversy surrounds the role of tocolytics, steroids and antibiotics. ${ }^{3}$

The aim of the study was to observe the risk factors and aetiology of late PPROM.

\section{METHODS}

\section{Source of Data}

100 patients of preterm premature rupture of membranes in between $34-37$ weeks' gestation admitted in labor room were studied after considering inclusion and exclusion criteria.

\section{Study Design \\ Descriptive study.}

\section{Study Period}

Over a period of two year from 1st Aug 2016 to 31st July 2018.

\section{Study Place}

Hi-Tech Medical College \& Hospital.

\section{Sample Size}

100

\section{Inclusion Criteria}

All pregnant women with a singleton pregnancy between 3437 weeks of gestational age with preterm premature rupture of membranes.

\section{Method of Collection of Data}

A detailed history was taken including age, booking, socioeconomic status, time of onset of leaking, amount of fluid lost, its colour, odour, association with pain or bleeding per vagina and perception of foetal movements.

General examination, height and weight were recorded. Systemic examination included cardiovascular, respiratory systems and CNS systems.

In the obstetric examination, following were noted. Height of uterine fundus, lie, presentation and position of foetus, engagement of presenting part, condition of uterus whether contracted or relaxed.

Uterine tenderness was looked for as a sign of chorioamnionitis. Foetal heart sound was auscultated, and its rate, rhythm and tone were noted. A sterile speculum examination was done and amniotic fluid pooling in posterior fornix was observed. The colour and smell of fluid was noted. If no fluid was seen, the patient was asked to cough, and drainage of fluid was looked for. In doubt, vaginal fluid specimen was collected and subjected to litmus paper test. Cervical swab was taken and sent for GrAM stain and culture sensitivity.

A single pelvic examination was done to note the Bishop's score, adequacy of pelvis, assessment of CPD and to rule out cord prolapse. Investigations like total count, differential count and C-reactive protein were done. Prophylactic antibiotic in the form of injection ampicillin 1 gm IV every 6 hourly was given.

\section{Statistical Analysis}

All relevant data will be compiled and entered into computer using computer-based software SPSS for appropriate analysis. Quantitative data will be analyzed by proportion and Chi square test at $p<0.05$ level of significance.

\section{RESULTS}

It is observed that PPROM was most common between age group 21-30 year. In this study $84 \%$ patients had maternal age group of 21-30 yrs.

\begin{tabular}{|c|c|c|}
\hline Age Group (Yr.) & No. of Mother & Percentage \\
\hline$<20$ & 7 & $07 \%$ \\
\hline $21-25$ & 49 & $49 \%$ \\
\hline $26-30$ & 35 & $35 \%$ \\
\hline $31-35$ & 06 & $06 \%$ \\
\hline$>35$ & 03 & $03 \%$ \\
\hline Total = & $\mathbf{1 0 0}$ & $\mathbf{1 0 0} \%$ \\
\hline \multicolumn{2}{|c|}{ Table 1. Age Distribution of Late PPROM } \\
\hline
\end{tabular}

\begin{tabular}{|c|c|c|}
\hline Socio Economic Status & No. of Mother & $\mathbf{\%}$ \\
\hline Low & 67 & 67 \\
\hline Middle & 28 & 28 \\
\hline High & 05 & 05 \\
\hline Total $=$ & $\mathbf{1 0 0}$ & $\mathbf{1 0 0}$ \\
\hline
\end{tabular}

Table 2. Socio-Economic Status in Cases of PPROM

This table shows $67 \%$ belong to low socioeconomic status. PPROM is predominant in low socioeconomic status.

\begin{tabular}{|c|c|}
\hline Gravidity & No. of Cases \\
\hline Primigravida & 61 \\
\hline Gravida - 2 & 29 \\
\hline Gravida - 3 & 05 \\
\hline Gravida - 4 & 05 \\
\hline Total $=$ & 100 \\
\hline \multicolumn{2}{|c|}{ Table 3. Gravidity Wise Distribution } \\
\hline
\end{tabular}

In above table PPROM was most common in Primigravida (61\%) or second gravida (29\%).

\begin{tabular}{|c|c|c|}
\hline ANC & No. of cases & Percentage \\
\hline Regular & 33 & $33 \%$ \\
\hline Irregular & 67 & $67 \%$ \\
\hline Total = & 100 & $100 \%$ \\
\hline
\end{tabular}

It is evident from the table that, the incidence of PPROM was higher in the group who do not avail regular antenatal care. 


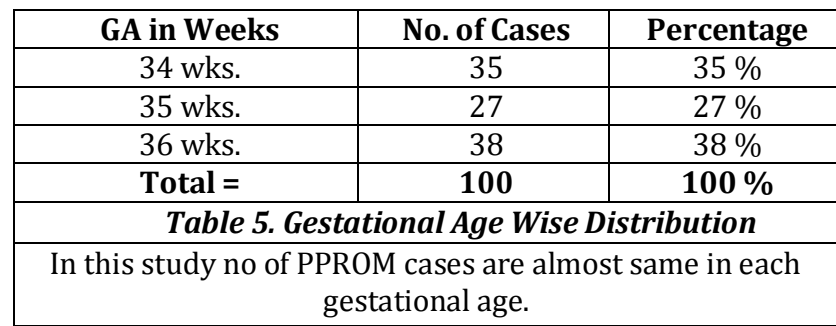

\begin{tabular}{|c|c|c|}
\hline $\begin{array}{c}\text { Time of Rupture of } \\
\text { Membrane }\end{array}$ & No. of Cases & Percentage \\
\hline $12 \mathrm{AM}-6 \mathrm{AM}$ & 42 & $42 \%$ \\
\hline $6 \mathrm{AM}-12 \mathrm{PM}$ & 28 & $28 \%$ \\
\hline $12 \mathrm{PM}-6 \mathrm{PM}$ & 15 & $15 \%$ \\
\hline $6 \mathrm{PM}-12 \mathrm{AM}$ & 15 & $15 \%$ \\
\hline
\end{tabular}

Table 6. Time of Rupture of Membrane (In shift)

From above table it is evident that the incidence of PPROM occurred in late hours of night and early morning hours.

\begin{tabular}{|c|c|c|}
\hline Risk Factor & No. of Cases & Percentage \\
\hline Unknown & 35 & $35 \%$ \\
\hline History of Recent Coitus & 23 & $23 \%$ \\
\hline Genital Tract Infection & 21 & $21 \%$ \\
\hline Travel History & 12 & $12 \%$ \\
\hline Previous history of PPROM & 09 & $09 \%$ \\
\hline \multicolumn{2}{|c|}{ Table 7. Risk Factors }
\end{tabular}

It is evident from above table that risk factors were unknown in $35 \%$ of cases, $\mathrm{H} / \mathrm{O}$ recent coitus $23 \%$ cases, genital tract infection $21 \%$ cases, travel history $12 \%$ cases, previous history of pprom in $9 \%$ cases.

\begin{tabular}{|c|c|c|}
\hline Organism Growth & $\begin{array}{l}\text { Vaginal Swab } \\
\text { Culture }\end{array}$ & $\begin{array}{l}\text { Urine } \\
\text { Culture }\end{array}$ \\
\hline No growth & 59 & 74 \\
\hline Group B Streptococcus & 09 & 01 \\
\hline E. coli & 14 & 18 \\
\hline Klebsiella & 08 & 03 \\
\hline N. gonorrhoea & 04 & 01 \\
\hline Staphylococcus & 03 & 01 \\
\hline Chlamydia & 03 & 02 \\
\hline \multicolumn{3}{|c|}{ Table 8. Culture Report in Late PPROM } \\
\hline $\begin{array}{l}\text { In this present study E. } \\
\text { found in both high }\end{array}$ & $\begin{array}{l}\text { li is the most co } \\
\text { sinal swab and } u\end{array}$ & $\begin{array}{l}\text { organism } \\
\text { culture. }\end{array}$ \\
\hline
\end{tabular}

\section{DISCUSSION}

Preterm PROM complicates $3-8 \%$ of pregnancies and leads to one third of preterm deliveries. ${ }^{2}$ It increases the risk of prematurity and leads to other perinatal and neonatal complications with $1-2 \%$ risk of foetal death. It is an observational study done in tertiary care hospital including 100 patients of preterm premature rupture of membranes in between 34-37 weeks' gestation admitted in labor room for a period of 2 year were studied.

\section{Maternal Age}

In this study PPROM was present in $84 \%$ of cases in the age group of 21-30 years. The high incidence in this age group can be related to sexual activity \& genital infection (Akhter et al 1980)

Khade et al (2014) found $79 \%$ of cases of PPROM are in the age group of 20-29 yrs.

\section{Socio-Economic Status}

In this study the patients of low socioeconomic status were $67 \%$ and middle socioeconomic status were $28 \%$ which is comparable with the study by Shehla et al (2010) which is $68.23 \%$ and $31.77 \%$ respectively. ${ }^{4}$ Studies have shown that defects in the amniotic membranes occur due to low socioeconomic status associated with factors like malnutrition, over exertion, poor hygiene, stress, high parity, recurrent genitourinary infection and anemia. The risk of PPROM increases with decrease antibacterial activity in the amniotic fluid of patients with low socio- economic status.

\section{Booked and Unbooked Cases}

In this study the booked cases were $33 \%$ and unbooked cases $67 \%$. In unbooked cases there is lack of antenatal care leading to lack of identification of recurrent risk factors like PPROM, preterm delivery, induced abortions and their managements. Also, urogenital infections are not detected and treated due to lack of antenatal care leading to PPROM.

\section{Parity}

Primigravida is a risk factor for PPROM due to increased sexual activity \& increased genital infection (Aktar et al, 1980). In this study $61 \%$ PPROM cases are primigravida.

\begin{tabular}{|c|c|c|c|c|c|}
\hline $\begin{array}{c}\text { Other } \\
\text { studies }\end{array}$ & Swathi $^{3}$ & Shehla $^{4}$ & Okeye $^{5}$ & Trinity $^{6}$ & $\begin{array}{c}\text { Our } \\
\text { Study }\end{array}$ \\
\hline Primi & $48 \%$ & $44.7 \%$ & $29.1 \%$ & $55.9 \%$ & $61 \%$ \\
\hline Multi & $52 \%$ & $55.3 \%$ & $69.9 \%$ & $44.1 \%$ & $39 \%$ \\
\hline \multicolumn{6}{|c|}{ Table 9. Comparison of Parity with Other Studies } \\
\hline
\end{tabular}

\section{Gestational Age Wise Distribution.}

In our study the incidence of PPROM at 34-35 wks, 35-36 wks., 36-37 wks. were almost same. This result is comparable to work of Breese (1961), Gillebrand (1967), and Pathak (1974).

\section{Time of Rupture of Membrane}

In the present study the incidence of PPROM was around $42 \%$ between $12 \mathrm{AM}$ to $6 \mathrm{AM}$, followed by $28 \%$ between $6 \mathrm{AM}$ to 12 am. This implies that most of the PPROM occurring in late hrs of night \& early morning. It has been observed that prom has circadian distribution where by the maximus cases occur between 2 AM to 4 am.

\section{Risk Factors Analysis}

This study shows different risk factors of PPROM like H/O recent coitus in $23 \%$ of cases, Genital tract infection in $21 \%$ cases, travel history $12 \%$, previous history of PPROM in $9 \%$ cases. No risk factor found in $35 \%$ cases.

Gunn et al, 1970 quoted genital tract infection as the major risk factors (40\%) along with coitus (16\%).

Flood and Nayee, 1984 studied 25, 820 patients with PROM and analysed 14 risk factors using multivariate analysis among which recent coitus was one of the leading risk factors.

\section{Investigations for Evidence of Infection}

The investigations like total count, C-reactive protein and high vaginal swab for culture and sensitivity were done to evaluate for the evidence of infection. Leukocytosis can be affected by pregnancy and labor. CRP estimates seem to be reliable monitoring tool (Carroll). ${ }^{7}$ But in more detailed studies WBC 
and CRP were poor predictors of the presence of a positive amniotic fluid or foetal blood culture. ${ }^{8}$

\section{Urine Culture and High Vaginal Swab Culture Report}

Swati Pandey, Anupama Deva, S. Bandi et al MGM medical college Indore, in their study found E.coli (28.57\%), Klebsiella (21.4\%)to be common aerobic \& Bacteroides fragilis (14.2\%) was the commonest anaerobic organism isolated. Surayapalem S. et al (2017) study showed that no bacterial growth was observed in $49 \%$ cases followed by E.coli (19\%), S.aureus (11\%), GBs and Citrobacter (each 2\%) of cervical swab culture.

High vaginal swab culture and urine culture was done in all patients with PPROM. The urine culture shows no growth in $74 \%$ cases, whereas $59 \%$ vaginal swab culture shows no growth.

The positive culture report of high vaginal swab shows E.coli (14\%), Gp.B Streptococcus (9\%), Klebsiella (8\%), N. gonorrhoea (4\%), Staph Aureus (3\%), Chlamydia trachomatis $(3 \%)$ cases.

The positive urine culture report shows E.coli (18\%), Gp.B Streptococcus (1\%), Klebsiella (3\%), N. gonorrhoea $(1 \%)$, Staph Aureus (1\%), Chlamydia (2\%) cases.

\section{CONCLUSIONS}

PPROM is a significant obstetric problem. Despite exhaustive research, most aspects of PPROM remain enigmatic. It is one of the important causes of preterm birth that can result in high perinatal morbidity and mortality along with maternal morbidity. Looking after a premature infant puts immense burden on the economy and health care resources of the country. Therefore, careful antenatal monitoring, detection and prompt treatment of infection is necessary. Strict aseptic precautions, appropriate therapy, regular follow up are important in prevention and management of PPROM. Close antenatal monitoring, identification of risk factors like cervicovaginal infection and their management play an important role in prevention of PPROM. An understanding of gestational age dependent neonatal morbidity and mortality is important in determining the potential benefits of conservative management of preterm PROM at any gestation. It is important that the patient should be well informed regarding the potential for subsequent maternal, foetal and neonatal complications regardless of the management approach. Tocolysis in women with PPROM is needed till completion of corticosteroid. Antenatal corticosteroids should be administered in women with PPROM. Routine antibiotic administration reduces maternal and neonatal morbidity. Antibiotic therapy also delays delivery, thereby allowing sufficient time for prophylactic prenatal corticosteroids to take effect. Danger of infection to both mother and foetus increases with increased duration of PPROM. Our experience to date from the available resources suggests that management of PPROM still requires critical study.

\section{ACKNOWLEDGMENTS}

Authors are thankful to all the faculty and staff members of the Department of Obstetrics and Gynaecology, "Hi-Tech Medical College \& Hospital", Bhubaneswar, India and the patients for their immense cooperation and support during the study period.

\section{REFERENCES}

[1] Caughey AB, Robinson JN, Norwitz ER. Contemporary diagnosis and management of preterm premature rupture of membranes. Rev Obstet Gynecol 2008;1(1):11-22.

[2] Arias F. Premature rupture of the membrane. Practical guide to high risk pregnancy and delivery. $3^{\text {rd }}$ edn. New Delhi: Elsevier 2008: p. 220-37.

[3] Pandey S, Dave A, Bandi S. Maternal and foetal outcome in cases of preterm premature rupture of membranes. J Obstet Gynaecol India 2000;50:63.

[4] Noor S, Fawwad A, Shahzad H, et al. Foetomaternal outcome in patients with or without premature rupture of membranes. J Ayub Medical College Abbottabad 2010;22(1):164-7.

[5] Okeke TC, Enwereji JO, Okoro OS, et al. The incidence and management outcome of preterm premature rupture of membranes in a tertiary hospital in Nigeria. Am J Clinic Med Res 2014;(2)1:14-7.

[6] Triniti A, Suthatvorawut S, Pratak 0. Epidemiologic study of cervical swab culture in preterm premature rupture of membrane (PPROM) at Ramathibodi Hospital. Thai J Obstet Gynaecol 2008;16(3):173-8.

[7] Carroll SG, Philpott-Howard J, Nicolaides KH. Amniotic fluid grAM stain and leukocyte count in the prediction of intrauterine infection in preterm prelabour amniorrhexis. Foetal Diag Therapy 1996;11(1):1-5.

[8] ACOG Committee on Practice Bulletins - Obstetrics. ACOG Practice Bulletin No 80: premature rupture of membranes. Clinical Management guidelines for Obstetrician - Gynecologists. Obstet Gynecol 2007;109(4):1007-19.

[9] Gunn GC, Mishell DR Jr, Morton DG. Premature rupture of the foetal membranes. A review. Am J Obstet Gynecol 1970;106(3):469-83. 